\title{
High hopes for RANKL: will the mouse model live up to its promise?
}

\author{
Tamara Tanos and Cathrin Brisken*
}

\begin{abstract}
The steroid hormones, estrogens and progesterone are key drivers of postnatal breast development and are linked to breast carcinogenesis. Experiments in the mouse mammary gland have revealed that they rely on paracrine factors to relegate their signal locally and to amplify it. In particular, RANKL is a key mediator of progesterone action. Systemic inhibition of RANKL blocked proliferation in the mammary epithelium with potential clinical implications: a RANKL-inhibiting antibody, Denosumab (Amgen), has been approved by the US Food and Drug Administration for osteoporosis treatment. Two publications now provide evidence that progestin-driven mouse mammary tumorigenesis can be blocked by ablating RANK signaling. Can the osteoporosis drug help breast cancer patients? The burning question now is whether the role of this pathway is conserved in the human breast and whether RANKL signaling has a role in the pathogenesis of one or more subtypes of breast cancer.
\end{abstract}

A role for progesterone in breast carcinogenesis is increasingly recognized. Breast cancer risk increases with the number of menstrual cycles a women experiences [1] and proliferation occurs in the breast epithelium during the luteal phase, when serum progesterone levels are high [2]. Moreover, postmenopausal women on hormone replacement therapy have increased breast cancer risk when taking combined estrogens and progestins but not with estrogens only [3].

Receptor activator of NF- $\mathrm{BB}$ ligand (RANKL) is a tumor necrosis factor (TNF) family member originally identified as a dendritic cell survival factor involved in the regulation of $\mathrm{T}$-cell-dependent immune response and

*Correspondence: cathrin.brisken@epfl.ch

Ecole polytechnique fédérale de Lausanne (EPFL), ISREC - Swiss Institute for Experimental Cancer Research, NCCR Molecular Oncology, SV2.832 Station 19, $\mathrm{CH}-1015$ Lausanne, Switzerland subsequently shown to control bone remodeling by inducing osteoclast differentiation [4]. Analysis of RANK- and RANKL-deficient mice pointed to a role for this pathway in the mammary gland during pregnancy [5] and in mammary carcinoma metastasis to the bone [6].

RANKL expression in the mammary epithelium is controlled by progesterone $[7,8]$. Recent work identified RANKL as a key paracrine mediator of progesteroneinduced mouse mammary epithelial cell proliferation $[9,10]$ and implicated the cytokine in stem cell control $[11,12]$. Systemic inhibition of RANKL signaling by intravenous injection of recombinant osteoprotegerin, its decoy receptor, blocked progesterone-induced proliferation in the mammary epithelium, suggesting RANKL may be used as a therapeutic target in the mammary gland [9].

Schramek and colleagues [13] and Gonzalez-Suarez and colleagues [14] now induced mammary carcinomas in mice using the progestin medroxyprogesterone acetate (MPA) and the mutagenic agent 7,12-dimethylbenz(a) anthracene (DMBA) and demonstrate that RANKL is a key factor in this process. Over-expression of RANK by means of a mouse mammary tumor virus (MMTV)driven transgene accelerated hyperplasia and tumor formation [14] whereas pharmacological inhibition of RANKL $[13,14]$ and genetic inactivation of RANK in the mammary epithelium [14] decreased incidence and delayed onset of tumorigenesis in this system.

To investigate whether RANKL is similarly important in the pathogenesis of other tumor types that arise independently of exogenous hormones, Gonzalez-Suarez and colleagues used the MMTV-neu transgenic mouse model. Interestingly, in ErbB2-driven carcinogenesis, pharmacological inhibition of RANKL also reduces tumor growth and lung metastasis, suggesting that the RANK signaling pathway may be of functional relevance in a wider tumor spectrum. This is of great clinical interest given the heterogeneity of human breast cancer. Schramek and colleagues observe that RANK deletion does not alter the incidence of mammary cancer in MMTV-neuT transgenic mice. It is conceivable that the apparent discrepancy results from Keratin5-cre RANK deleted cells being outgrown by MMTV-neuT cells that have kept the wild-type RANK allele. 
Importantly, Gonzalez-Suarez and colleagues demonstrate that Fc-RANK inhibits proliferation of normal mammary epithelium and hyperplasias, but not in carcinomas, suggesting RANKL inhibition would be useful in early stages of tumorigenesis and/or as a preventive drug.

Can these findings be extrapolated to humans? Dissociation of hormone receptor expression and proliferation in the adult mammary gland is a phenomenon that is conserved between human and rodents (reviewed in [15]), suggesting that paracrine signals are also of relevance to the human breast. Caution is required as it is unclear whether the paracrine circuitry is shared between the two species or whether the human breast may rely on distinct factors.

Immunostainings of human breast carcinomas reveal that RANKL is expressed in $11 \%$ of human tumors. There is no evidence for colocalization within the epithelium for receptor and ligand but expression is found in some stromal cells [14]. This raises the possibility that the scenario is more complex in human breast cancer than in the present mouse tumor models with infiltrating immune cells providing the ligand. In any case, this drug seems too palatable not to try! The challenge lies in designing clinical trials with short endpoints and identifying adequate preclinical models to identify swiftly which particular patients may benefit from the drug.

\section{Abbreviations}

MMTV, mouse mammary tumor virus; RANK, receptor activator of NF-kB;

RANKL, receptor activator of NF-kB ligand.

\section{Competing interests}

The authors declare that they have no competing interests.

Published: 28 January 2011

\section{References}

1. Kelsey JL, Gammon MD, John EM: Reproductive factors and breast cancer. Epidemiol Rev 1993, 15:36-47.

2. Ramakrishnan R, Khan SA, Badve S: Morphological changes in breast tissue with menstrual cycle. Mod Pathol 2002, 15:1348-1356.
3. Chlebowski RT, Kuller LH, Prentice RL, Stefanick ML, Manson JE, Gass M, Aragaki AK, Ockene JK, Lane DS, Sarto GE, Rajkovic A, Schenken R, Hendrix SL, Ravdin PM, Rohan TE, Yasmeen S, Anderson G; WHI Investigators: Breast cancer after use of estrogen plus progestin in postmenopausal women. $N$ Engl J Med 2009, 360:573-587.

4. Nakashima T, Takayanagi $\mathrm{H}$ : Osteoimmunology: crosstalk between the immune and bone systems. J Clin Immunol 2009, 29:555-567.

5. Fata JE, Kong YY, Li J, Sasaki T, Irie-Sasaki J, Moorehead RA, Elliott R, Scully S, Voura EB, Lacey DL, Boyle WJ, Khokha R, Penninger JM: The osteoclast differentiation factor osteoprotegerin-ligand is essential for mammary gland development. Cell 2000, 103:41-50.

6. Jones DH, Nakashima T, Sanchez OH, Kozieradzki I, Komarova SV, Sarosi I, Morony S, Rubin E, Sarao R, Hojilla CV, Komnenovic V, Kong YY, Schreiber M, Dixon SJ, Sims SM, Khokha R, Wada T, Penninger JM: Regulation of cancer cell migration and bone metastasis by RANKL. Nature 2006, 440:692-696

7. Brisken C, Ayyannan A, Nguyen C, Heineman A, Reinhardt F, Tan J, Dey SK, Dotto GP, Weinberg RA: IGF-2 is a mediator of prolactin-induced morphogenesis in the breast. Dev Cell 2002, 3:877-887.

8. Mulac-Jericevic B, Lydon JP, DeMayo FJ, Conneely OM: Defective mammary gland morphogenesis in mice lacking the progesterone receptor $B$ isoform. Proc Natl Acad Sci U S A 2003, 100:9744-9749.

9. Beleut M, Rajaram RD, Caikovski M, Ayyanan A, Germano D, Choi Y, Schneider P, Brisken C: Two distinct mechanisms underlie progesterone-induced proliferation in the mammary gland. Proc Natl Acad Sci U S A, 107:2989-2994.

10. Fernandez-Valdivia R, Mukherjee A, Ying Y, Li J, Paquet M, DeMayo FJ, Lydon $J P$ : The RANKL signaling axis is sufficient to elicit ductal side-branching and alveologenesis in the mammary gland of the virgin mouse. Dev Biol 2009, 328:127-139.

11. Joshi PA, Jackson HW, Beristain AG, Di Grappa MA, Mote PA, Clarke CL, Stingl J, Waterhouse PD, Khokha R: Progesterone induces adult mammary stem cell expansion. Nature, 465:803-807.

12. Asselin-Labat ML, Vaillant F, Sheridan JM, Pal B, Wu D, Simpson ER, Yasuda H, Smyth GK, Martin TJ, Lindeman GJ, Visvader JE: Control of mammary stem cell function by steroid hormone signalling. Nature, 465:798-802.

13. Schramek D, Leibbrandt A, Sigl V, Kenner L, Pospisilik JA, Lee HJ, Hanada R, Joshi PA, Aliprantis A, Glimcher L, Pasparakis M, Khokha R, Ormandy CJ Widschwendter M, Schett G, Penninger JM: Osteoclast differentiation factor RANKL controls development of progestin-driven mammary cancer. Nature, 468:98-102

14. Gonzalez-Suarez E, Jacob AP, Jones J, Miller R, Roudier-Meyer MP, Erwert R, Pinkas J, Branstetter D, Dougall WC: RANK ligand mediates progestin-induced mammary epithelial proliferation and carcinogenesis. Nature, 468:103-107.

15. Brisken C, O'Malley B: Hormone action in the mammary gland. Cold Spring Harb Perspect Biol 2010, 2:a003178.

doi: $10.1186 /$ bcr2805

Cite this article as: Tanos T, Brisken C: High hopes for RANKL: will the mouse model live up to its promise? Breast Cancer Research 2011, 13:302. 